\title{
Stretching-Driven Crystal Anisotropy and Optical Modulations of Flexible Wide Bandgap Inorganic Thin Films
}

Hong Je Choi, Woosun Jang, Young Eun Kim, Aloysius Soon and Yong Soo Cho*

Department of Materials Science and Engineering, Yonsei University, Seoul 03722, Korea *Corresponding author: ycho@yonsei.ac.kr (Y. S. Cho) 


\section{Estimation of internal stress occurring in $\mathrm{ZnS}$ thin films}

For the $\mathrm{ZnS}$ thin films processed with an applied in situ stress, the lattice constant $a$ was determined from the equation $a=d\left(h^{2}+k^{2}+l^{2}\right)^{1 / 2}$, where $h, k$, and $l$ denote the lattice plane index; $d$ is the inter-planar spacing, which was evaluated from Bragg's relation, $d=n \lambda / 2 \sin \theta$. The resultant internal stress $\sigma$ in the $\mathrm{ZnS}$ thin films was determined from, ${ }^{1,2}$

$$
\sigma=\frac{E\left(a-a_{0}\right)}{2 a_{0} v}
$$

where $E, a$, and $a_{0}$ are the Young's modulus of $\mathrm{ZnS}(75 \mathrm{GPa}),{ }^{3}$ lattice constant, and lattice constant of the unstrained sample, respectively. The $\sigma$ values calculated from Eq. (1) are plotted as a function of the applied strain in the $\mathrm{ZnS}$ thin films (Figure S1).

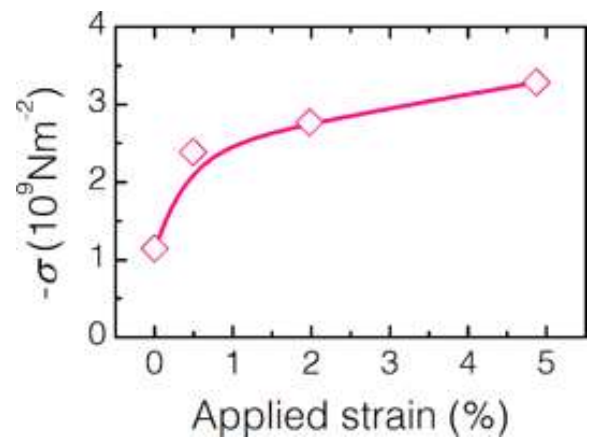

Figure S1. Variation of the estimated internal stress with applied strain in $\mathrm{ZnS}$ thin films. 


\section{Estimated structural parameters of $\mathrm{ZnS}$ thin films}

Table S1. Interplanar spacing of (200) and (111) planes, calculated lattice constants $a$ and $c$, lattice strains, and $c / a$ ratio, which were extracted from the TEM analysis of $\mathrm{ZnS}$ thin films processed with applied in-situ strain.

\begin{tabular}{ccccc}
\hline \multirow{2}{*}{ Parameter } & \multicolumn{4}{c}{ Applied strain (\%) } \\
& 0 & 0.49 & 1.98 & 4.87 \\
\hline$d_{200}(\AA)$ & 2.721 & 2.685 & 2.674 & 2.663 \\
$d_{111}(\AA)$ & 3.142 & 3.122 & 3.119 & 3.115 \\
$a(\AA)$ & 5.437 & 5.370 & 5.348 & 5.326 \\
$\varepsilon_{a}(\%)$ & 0 & -1.23 & -1.73 & -2.04 \\
$c(\AA)$ & 5.442 & 5.485 & 5.511 & 5.533 \\
$\varepsilon_{c}(\%)$ & 0 & 0.78 & 1.27 & 1.84 \\
$c / a$ & 1.001 & 1.021 & 1.028 & 1.040 \\
\hline
\end{tabular}

Table S2. Atomic distance $l_{\mathrm{Zn}-\mathrm{S}}$ and bonding angles $g_{1}$ and $g_{2}$ (estimated by the VESTA program) in $\mathrm{ZnS}$ thin films processed with applied in-situ strain.

\begin{tabular}{ccccc}
\hline \multirow{2}{*}{ Parameter } & \multicolumn{4}{c}{ Applied strain (\%) } \\
& 0 & 0.49 & 1.98 & 4.87 \\
\hline$l_{\text {Zn-S }}(\AA)$ & 2.356 & 2.345 & 2.339 & 2.334 \\
$g_{1}$ (deg.) & 109.47 & 108.32 & 107.87 & 107.40 \\
$g_{2}$ (deg.) & 109.47 & 110.05 & 110.28 & 110.52 \\
\hline
\end{tabular}

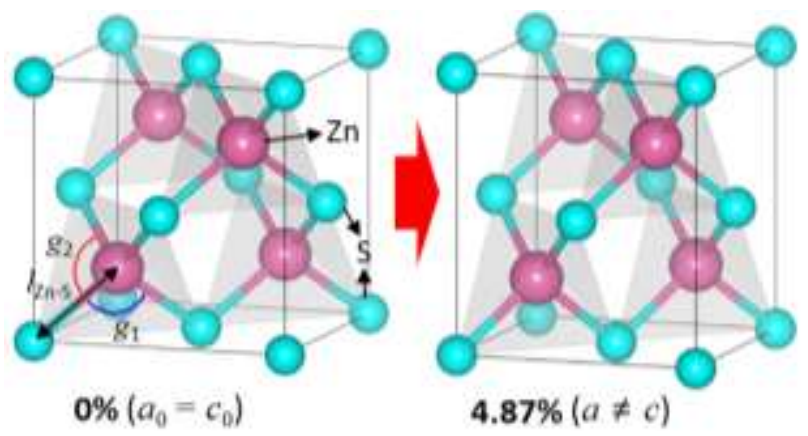

Figure S2. Schematic crystal structures reflecting unit cell distortions of the $4.87 \%$-strained $\mathrm{ZnS}$ thin films relative to the unit cell of the unstrained sample. 
III. Plots of $1 /\left(n_{f}^{2}-1\right)$ versus $(h v)^{2}$ in $\mathrm{ZnS}$ thin films

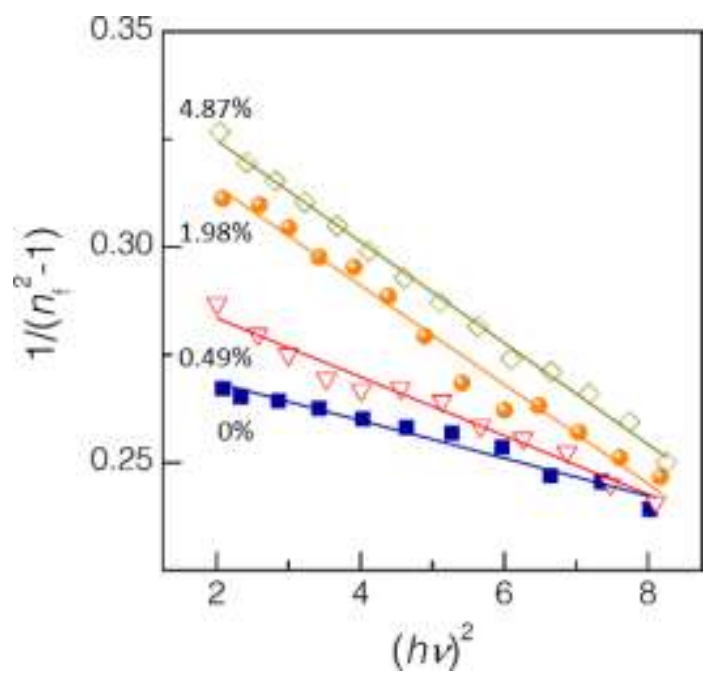

Figure S3. Plots of $1 /\left(n_{f}^{2}-1\right)$ versus $(h v)^{2}$ for the $\mathrm{ZnS}$ thin films processed with different levels of applied strain.

\section{References}

(1) I. C. Noyan, J. B. Cohen, Residual Stresses: Measurement by Diffraction and Interpretation, Springer-Verlag New York, NY, USA 1987.

(2) A. Portinha, V. Teixeira, J. Carneiro, M. G. Beghi, C. E. Bottani, N. Franco, R. Vassen, D. Stoever, A. D. Sequeira, Surf. Coat. Technol. 2004, 188-189, 120-128.

(3) Y. P. V. Subbaiah, P. Prathap, K. T. R. Reddy, Appl. Surf. Sci. 2006, 253, 2409-2415. 